\title{
How to reduce the impact of container flows generated by a maritime terminal on urban transport
}

\author{
D. Ambrosino \& A. Sciomachen \\ DIEM - Università di Genova, Italy
}

\begin{abstract}
One serious problem seaports face today is the lack of space at maritime terminals and the growing congestion on their access routes with the inland connections. Moreover, environmental factors, regulation plans and topological constraints often prevent maritime terminal expansions. Therefore, it is now generally accepted that a strategic choice related to maritime terminals is a "dry port" policy, especially when terminals are located in urban and suburban areas, characterized by heavy commercial traffic.

In this work, we deal with the evaluation of possible locations for freight modal terminals with the aim of reducing the impact of containers transport on urban mobility. In particular, we use classical simple plant location algorithms for determining optimal sites on a connected intermodal network, where arc weights refer to costs arising from the transport of standardised units via different modalities. We focus our analysis on the logistic network in the Italian north-western regions, taking into a proper account the needs of the seaport network of the Liguria County and the most congested nodes in the transportation network of the city of Genoa. Related results are presented.
\end{abstract}

Keywords: multimodal transportation network, location problem, dry port, urban areas.

\section{Introduction and problem definition}

Over the years, and particularly in the last decade, maritime containerized transport has increased its performance significantly, while the size of the today's containerships is doubled, up to 14000 Twenty-foot Equivalent Units (TEU). Consequently, the main problems seaports face today are the lack of 
space at maritime terminals and the growing congestion on their access routes with the inland connections, especially considering the road modality (de Langed and Chouly [1]).

Environmental factors, regulation plans and topological constraints often prevent maritime terminal expansions. Therefore, it is now generally accepted that the necessary strategic choice with regard to maritime terminals is a "dry port" policy, especially with respect to maritime terminals located in urban and suburban areas characterized by heavy commercial traffic.

The dry port concept is based on a maritime terminal directly connected by rail or inland multimodal terminals, where containers can be collected, stored and handled as they were in a maritime terminal, waiting for their successive destination. In this context, dry ports aims at reducing the heavy traffic (Roso et al. [2]). Particularly interesting in the context of this paper seems to be the midrange dry port model, that is a dry port usually located halfway between the port and the inland, where it is possible to provide port services. A mid-range dry port plays the role of concentrating the import/export flow to/from maritime terminals. The connections between it and the port infrastructures are both road and railway, even if the access of heavy trucks is usually left outside the marine front end, while the containers flow is mainly routed via rail, which is provided by dedicated rail lines carried by shuttle trains. As shown in Roso and Lumsden [3] another advantage of mid-range dry ports is that, if they are opportunely located, can be very attractive also for the local enterprises and shipping companies, thus favoring an increase of the local economies.

In this work, we focus on the problem of defining optimal locations for midrange dry ports in order to reduce the impact of container transport on the urban mobility in the city of Genoa, Italy that has to share its heavy freight traffic with the daily commercial and private ones.

Noticeable attention has been recently paid to intermodal freight transport research and its development issues (see e.g. Jarzemskiene [4], and Macharis and Bontekoning [5]). In this direction, only relatively few works have been devoted to location problems for logistic platforms in urban and metropolitan areas. However, the negative impact of containerized flow from maritime terminals to the heavy traffic in central and suburban areas is well known. Indeed, there is the need of freight modal terminals able to facilitate inland connections with other transport modality while reducing the number of trucks that can be deviated to urban logistic platforms (see, e.g. Crainic et al. [6] and Leinbach and Capineri [7]), thus in turn reducing the air and noise pollution.

In this perspective, one of the today's open problems is to identify where to locate transhipment depots for freight transport in urban areas, taking into account the urban configuration and the logistic network. In this work we deal with such problem, focusing our attention on those nodes within an intermodal transportation network that has origin from maritime terminals located in urban areas, that could be attractive poles for modal exchanges for freight mobility, being also strategic locations within the overall network.

Usually, the hub location problem and its generalization applied to real life sized instances is solved with efficient heuristics, as the ones proposed by 
Chen [8], and by Silva and Cunha [9] for the case without capacity of the facilities. The state of the art of the solution methods for the hub location problem is presented by Alumur and Kara [10].

Here, inspired by a previous work [11], we use classical simple plant location algorithms for determining optimal sites on a connected intermodal network, where weights associated with the arcs refer to costs arising from the transport of standardized units via different modalities. We focus our analysis to the logistic network of the Italian north-western regions and evaluate suitable sites for being fruitfully selected as mid-range dry ports, taking into a proper account the needs of the seaport network of the Liguria County and the flow capacity of the most congested nodes in the urban transportation network of the city of Genoa.

The rest of the paper is organized as follows. In Section 2 we present the logistic network, and the related model, from the port of Genoa to the inland, giving particular emphasis to the flow capacity of the main highway accesses in the urban area. The proposed method for evaluating optimal locations for middry ports is reported in Section 3, together with some conclusion and outlines for future work.

\section{The logistic network model from urban marine terminals to their inland connections: the case of Genoa}

To better understand the main goal of the present paper, that is to determine inland locations for reducing as much as possible heavy traffic departing from maritime terminals located in urban areas, let us first give some information about the traffic flow in the city of Genoa and its port.

The port of Genoa is the natural access to the sea for northern Italy's most industrialized counties. According to the data provided by the Port Authority [12], in 2009 throughout the port of Genoa passed more than 58 million of tons of goods and 1.200.000 TEUS. The port surface is about 700 hectares, while its costal extension is about $15 \mathrm{~km}$, from the mouth of Bisagno River to Voltri, where there is another very active maritime terminal, named VTE. Between the east side of the port, that is actually location "Porto Antico" in the hearth of the city, to the western side, that is Voltri, there are four maritime container terminals. The map of the area where the port of Genoa is located is reported in Figure 1, where relevant site for our analysis, that is Port $(P)$, Voltri $(V O L)$ and Sampierdarena $(S A M)$ are explicitly indicated. In fact, Voltri and Sampierdarena are critical sites from a traffic point of view, mainly due to their access to the highway. In particular, the average flow at the highway barrier of Voltri going out of the city in rush hours is about 2400 vehicles per hour, while in the opposite direction we can count about 2000 vehicles. However, note that the main parallel urban streets going from $S A M$ to $V O L$ have a maximum flow capacity of 700 and 300 vehicles per hour, respectively. As for site $S A M$ is concerned, counting the main accesses to it, the maximum allowable flow capacity is about 2500 vehicles per hour, while at the barrier the hourly capacity is 2800 vehicles. 


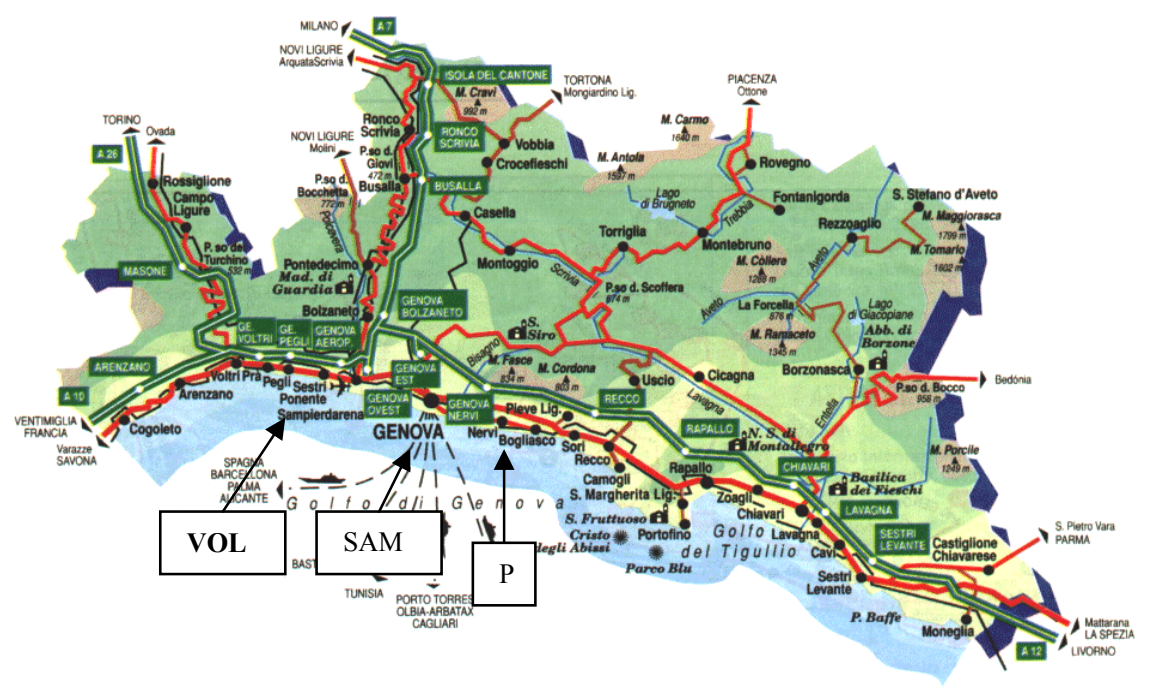

Figure 1: $\quad$ Map of the urban area of Genoa.

These data make evidence of the dramatic impact that container flows moving to/from maritime terminals have on the daily car circulation in the whole urban area, thus causing serious congestion problem. It is hence interesting to analyze alternatives for easily routing the container flows outside the marine front end. For this reason, let us focus on the logistic network covering the Italian northwestern regions, departing from the port of Genoa, with the aim of evaluating, among the possible multimodal freight nodes, what is the best location, no farther than $80 \mathrm{~km}$, for collecting containers, possibly sent via rail, and carrying out port operations.

Connections between Genoa and inland freight logistic platforms are possible both via rail and road; however, nowadays there is still a relevant unbalance in the modal split, since road transportation is about $70 \%$ of the total container traffic along the main direction towards north Europe.

As far as the railway freight transportation network, there are two main lines from Genoa to the north-western Italian regions, namely "Giovi" and "Succursale". However, the "Giovi" line has a high slope that significantly reduces its potentiality due to the consequently limit on the length and weight of the wagons. These lines serve both the freight and passenger mobility to/from the main cities. Considering the road connections, there are two main highways, going from Genoa respectively to Piemonte and Lombardia counties.

Having in mind the above geographical information, let us derive the corresponding network model.

A logistic network for the location problem is represented by a weighted multimodal graph $G=(V, E)$, where $V$ is the set of $n$ nodes and $E$ is the set of $m$ arcs connecting pairs of nodes. Usually, $V$ contains a subset $V_{H} \subset V$ of $h$ nodes 
representing the possible candidates for being the required facility location sites. $E=\bigcup_{k=1, t} E_{k}$, where set $E_{k}$ represents the arcs traveled in $G$ using the $k$-th transportation modality. To each arc $(i, j) \in E_{k}$ is associated a weight $w_{i j}$ representing the traveling cost for moving from $i$ to $j$ using transportation modality $k, k=1, \ldots, t$. Extension of standard network models allow to associate a $p$-dimensional row vector $\mathbf{w}$ to arcs of $E$ for representing different performance measures. In this paper we assume $p=2$; in particular, we consider as arc weight the corresponding distance $l_{i j}$ (expressed in $\mathrm{km}$ ), and the traveling monetary cost $c_{i j}$ (expressed in Euro), $\forall(i, j) \in E_{k}, k=1, . ., t$. Moreover, here we fix $t=2$ and $E$ $=E_{D} \cup E_{R}$, where arcs of $E_{D}$ are travelled by long vehicles or trucks mainly on the highway, while arcs belonging to $E_{R}$ represent the railway connections.

The logistic network model covering the Italian north-western regions, reported in Figure 2, has $n=16$ nodes and $m=94$ arcs, considering both directions; in particular, $h=12,\left|E_{D}\right|=50\left|E_{R}\right|=44$. Note that nodes belonging to $V_{H}$ are possible sites for freight terminal platforms, located nearby maritime terminals, and district parks.

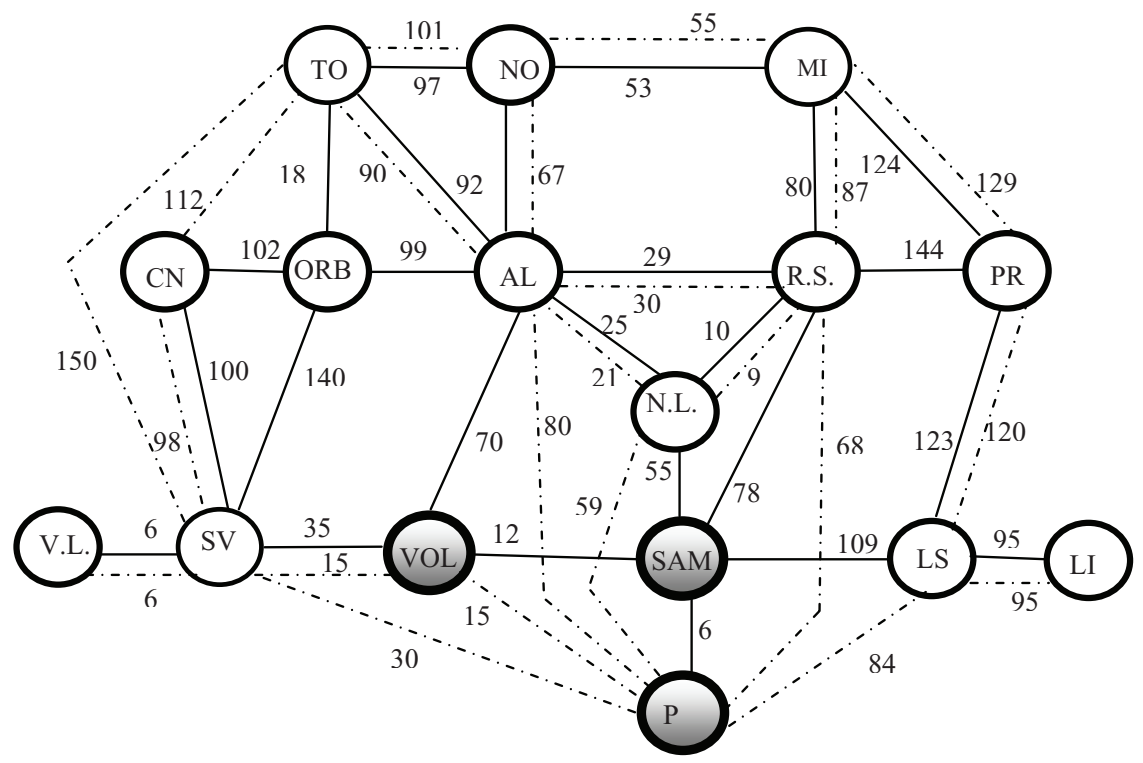

Figure 2: The intermodal logistic network of the Italian north-western regions.

Arcs of $E_{D}$ are depicted with lines representing highway or road connections, while dotted arcs are railway lines that are arcs of $E_{R}$. We report on the arcs only weights representing the corresponding distance (expressed in $\mathrm{km}$ ), while details about the costs related to the chosen modality will be given in the next section. In Figure 2, nodes representing the urban area of Genoa reported in Figure 1, 
namely $P, S A M$ and $V O L$, are enhanced with filled circles. The meaning of all nodes of the network is as follows.

P Port of Genoa

SAM Highway downtown connection

VOL Maritime terminal and west side highway connection

SV Port of Savona

V.L. Port of Vado Ligure

$\mathrm{CN}$ District park of Cuneo

ORB District park of Orbassano

TO Turin

MI Milan

AL District park of Alessandria

NO District park of Novara

N.L. District park of Novi Ligure

R.S. District park of Rivalta Scrivia

PR District park of Parma

LI Livorno

LS Port of La Spezia.

Note that nodes AL and N.L. are relevant sites for rail connections, since they belong to the main directions towards north Europe. Moreover, AL is the node where presently containers from the Ligurian ports are sorted and routed to other destinations. Finally, LS and V.L. are very active maritime terminals too.

Looking at Figure 2, readers can note that the network is relatively small, thus the optimal location for mid-range dry ports can be easily defined, even if it is necessary to deal with multimodal shortest path algorithms. However, the method we are going to present in the next section for the optimal location problem can be usefully applied to any logistic network $\forall n, m \in G$.

\section{The underlying location problem and the solution method}

Classical criteria for defining optimal locations suggest considering either a minmax rule, aimed at favouring the maximum distance from the selected node, or a minimum one, for which the node having the average minimum distance from all others is chosen [10]. In this direction, usually either the centre $\phi$ or the median node $\mu$ of the network is defined. However, when location problems rely on logistic multimodal network models, these optimal criteria are not anymore sufficient; in fact, it is also very important to analyse all transportation modalities that can guarantee easy connections among nodes, and their allowable combinations. Unfortunately, very few papers in the recent literature deal with location problem in multimodal network. Ambrosino and Sciomachen [11] proposed a heuristic procedure for restricting the set of possible candidate nodes of $V_{H}$ for being logistic platform, procedure aimed at facilitating the analysis of the possible ways of combining transportation modalities for travelling origin destination paths. 
Inspired by the procedure proposed in [11], here we present another algorithm that combines the above selection criteria and a new one in order to define a subset $V_{H(B)}$ of nodes belonging to $V_{H}$, thus limiting the choice of the node to be selected as the required mid-range dry port.

Let us hence define first both $\mu$ and $\phi$ separately according to the involved transportation modality; that is, we compute values $\mu_{k}$ and $\phi_{k}$, for $k=1, \ldots, t$. Moreover, let us consider an ad hoc multimodal connectivity criterion; in particular, assume that a node $i \in V_{H}$ can be profitably selected for being a midrange dry port only if it is very efficiently connected with the other nodes of the network, along all allowable transportation modalities. For each node $i \in V_{H}$ we are then interested in the computation of value $\Delta_{i}$, such that $\Delta_{i}=\sum_{k=1, \ldots, t} \sum_{j \in V} d_{i j k} / t$, where $d_{i j k}$ is the minimum travelling distance between node $i \in V_{H}$ and node $j \in V$ when transportation modality $k$ is chosen. $\Delta_{i}$ is hence the average sum of the shortest path between node $i$ and all nodes of the network, $\forall i \in V_{H}$, counting all travelling modes. Consequently, let $\delta=\operatorname{argmin}\left(\Delta_{i}\right)$ the node corresponding to the minimum distance value, that is the best connected node. Analogously, let $\Pi_{i}=\sum_{k=1, \ldots, t} \sum_{j \in V_{H}} d_{j i k} / t$ be the average sum of the shortest paths from all nodes of $V$ to node $i, \forall i \in V_{H}$, and $\tau=\operatorname{argmin}\left(\Pi_{i}\right)$ the corresponding most easily reachable node. In other words, nodes $\delta$ and $\tau$ well perform in terms of connection to the other nodes of the network. It is worth noting that in case of not oriented network obviously $\delta=\tau$.

We restrict our locative choice to nodes $\delta$ and $\tau$, and to the classical median and centre nodes $\mu$ and $\phi$, computed considering separately each transportation modality. Therefore, let $V_{H(B)} \subseteq V_{H}$, such that $\left|V_{H(B)}\right|=b \leq h$, be the set of candidate sites, that is the subset of possible logistic platforms that could be selected as mid-range dry ports.

Once the restricted set $V_{H(B)}$ of possible candidate nodes is defined, we apply a heuristic algorithm for finding optimal multimodal origin $(o)$ - destination $(d)$ routes in network $G$. In practice, we have to evaluate $2 k b(n-h)$ connections between pairs of node $i$, $j$, where $i \in V_{H(B)}$ and $j \in V$, and select node $i^{*}$ belonging to $V_{H(B)}$ such that the multimodal cost of the path from $o$ to $i^{*}$ and from $i^{*}$ to $d$ is the minimum one.

Summarizing, the whole proposed procedure consists of the following steps. For each transportation modality $k, k=1, \ldots, t$, take as input the $n \times n$ cost matrix and the $n \times n$ distance matrix referring to the $k$-th transportation modality;

1. compute the all pair shortest paths on $G$;

2. determine the median node $\mu_{k}$ of network $G$;

3. determine the centre node $\phi_{k}$ of network $G$;

4. determine nodes $\delta$ and $\tau$;

5. define subset $V_{H(B)} \subseteq V_{H}$; 
6. for each candidate node $i, i=1, \ldots, b$, for each pair of $o$ - $d$ nodes in $V \backslash V_{H}$ evaluate the cost of path $(o \rightarrow i) \rightarrow(i \rightarrow d)$;

7. choose $i^{*}$ such that $\left(o \rightarrow i^{*}\right) \rightarrow\left(i^{*} \rightarrow d\right)$ is the least multimodal cost path.

Note that the computational complexity of the whole procedure is $\mathrm{O}\left(t n^{3}\right)$, due to step 1; this means that the procedure can be easily performed independently on the size of network $G$.

Let us hence follows the above procedure and define the best location within the given network, considering the road and rail transportation modality, and a combination of both. Note that in case of the logistic network given in Figure 2, we consider only paths departing from node $P$, focusing the attention on the possible freight platform nodes in $V_{H}$, that is the actual district parks and maritime terminals; such nodes can be easily identified in $G$ since they have at least one entering and one outgoing arc belong to both $E_{D}$ and $E_{R}$.

In the computation, the $n \times n$ cost matrix related to the road and rail modalities has been derived starting from the corresponding distance matrix. In particular, road costs have been computed including toll, if any, the fuel, and the fee of the truck driver, while rail costs have been derived according to the tariffs provided by Trenitalia, the society holding the railway network, and refer to the transportation of standard 20 TEUs container. In particular, the applied tariffs are reported in Table 1.

Table 1: $\quad$ Rail transportation cost.

\begin{tabular}{|l|l|}
\hline KM & Cost (Euro) \\
\hline $1-100$ & 15,52 \\
\hline $101-125$ & 15,72 \\
\hline $126-150$ & 15,97 \\
\hline $151-175$ & 16,27 \\
\hline $176-200$ & 16,62 \\
\hline $201-225$ & 17,02 \\
\hline
\end{tabular}

By applying the above procedure we get, in the order: $\mu_{D}=\mathrm{RS} ; \mu_{R}=\mathrm{NL} ; \phi_{D}$ $=\mathrm{SV} ; \phi_{R}=\mathrm{NL}, \mathrm{RS}, \mathrm{SV}, \mathrm{VL} ; \delta=\tau=\mathrm{NL}$. Consequently, we define set $V_{H(B)}=$ $\{\mathrm{NL}, \mathrm{RS}, \mathrm{SV}, \mathrm{VL}\}$. At step 6, since our goal is to reduce container flow at the congested nodes closed to maritime terminals, we perform our computation assuming that the origin node is left only travelling on the railway line, while successive connections from the mid-range dry port to the final destination belong either to $E_{D}$ or $E_{R}$. Let us suppose that final destinations are nodes $T O$ and $M I$, that is the main cities towards north Europe in the considered geographical area.

The cost of the resulting possible paths, either mono or multimodal ones, is reported in Table 2, where all nodes in subset $V_{H(B)}$ are evaluated as modal change node.

Readers can see that the most economic solution is to select as mid-range dry port node $R S$, reaching the final destination, in one case, that is going to $M I$, on the road network, while on the railway network when containers go to $T O$. 
Table 2: Cost of the path throughout the selected restricted freight logistic nodes.

\begin{tabular}{|lllll|}
\hline Path $(\boldsymbol{o}, \boldsymbol{i})$ & Cost on $\mathbf{E}_{\mathbf{R}}$ & Path $(\boldsymbol{i}, \boldsymbol{d})$ & Cost on $\mathbf{E}_{\mathbf{R}}$ & Cost on $\mathbf{E}_{\mathbf{D}}$ \\
(P,NL) & 15,52 & (NL,MI) & 15,52 & 11,24 \\
(P,RS) & 15,52 & (NL,TO) & 15,72 & 17,80 \\
(P,SV) & 15,52 & (SV,TO) & 15,97 & 17,83 \\
(P,VL) & 15,52 & (SV,MI) & 16,62 & 23,68 \\
& & (VL,MI) & 16,62 & 24,38 \\
& & (VL,TO) & 16,27 & 18,60 \\
& & (RS,MI) & 15,52 & 9,98 \\
& & (RS,TO) & 15,72 & 17,80 \\
\hline
\end{tabular}

\section{Acknowledgement}

This work has been partially supported by the Italian MURST Prin project 2007 N. 2007J494P3_005: "Models for managing freight flows in maritime terminals, logistic platforms and multi-modal transportation networks".

\section{References}

[1] de Langed, P.W., Chouly, A. Hinterland access regimes in seaports. European Journal of Transport and Infrastrucure Research, Vol. 4 No. 4, pp. 361-80, 2004.

[2] Roso, V., Woxenius, J., Lumsden, K., The dry port concept: Connecting container seaports with the hinterland. Journal of Transport Geography, Vol. 17, No 5, pp. 381-98, 2009.

[3] Roso, V., Lumsden, K., A review of dry ports. Maritime Economics \& Logistics 12, pp. 196-213, 2010.

[4] Jarzemskiene I., The evolution of multimodal transport research and its development issues. Transport 22, 4, pp. 296-306, 2007.

[5] Macharis C, Bontekoning Y.M., Opportunities for o.r. in intermodal freight transport research: a review. European Journal of Operational Research 153(2), pp. $400-416,2004$.

[6] Crainic T.G., Ricciardi N., Storchi G., Advanced freight transportation systems for congested urban areas. Transportation Research Part C, 12, pp. 119-137, 2004.

[7] Leinbach T.R., Capineri C., Globalized Freight Transport: Intermodality, E-commerce, Logistics and Sustainability, Edward Elgar, Cheltenham, UK, Northampton, MA, USA, 2007.

[8] Chen J.F., A hybrid heuristic for the uncapacitated single allocation hub location problem. Omega, 35, 2, pp. 211-220, 2007.

[9] Silva M.R., Cunha C.B., New simple and efficient heuristics for the uncapacitated single allocation hub location problem. Computers \& Operations Research, 36, pp. 3152 - 3165, 2009. 
88 Sustainability Today

[10] Alumur S., Kara B.Y., Network hub location problems: The state of the art. European Journal of Operation Research, 190 pp. 1-21, 2008.

[11] Ambrosino D., Sciomachen A., Location of logistic platforms within urban transportation networks. Proceedings Mathematical Problems in Engineering, Aerospace and Sciences, Cambridge Scientific, pp. 672-680, 2009.

[12] www.porto.genova.it 